\title{
Probabilistic relationships between strain range, stress range and loading cycles. Application on ASTM A969 steel
}

\author{
Paul Dario Toasa Caiza*, Thomas Ummenhofer \\ KIT Stahl- und Leichtbau, Versuchsanstalt für Stahl, Holz und Steine, Karlsruher Institut für Technologie (KIT), Germany
}

Keywords:

Stress-life

Strain-life

Cyclic loading

Weibull distribution

Stüssi model

\begin{abstract}
A B S T R A C T
Fatigue life estimations can be made by considering the $\Delta \sigma-N$ or $\Delta \epsilon-N$ curves. Reliable estimations allow engineers designing save stress levels in structures or machines. In this paper, the Weibull distribution is combined with the Stüssi function to model the quantiles of the $\Delta \sigma-N$ and $\Delta \epsilon-N$ curves and the Ramberg-Osgood relationship. The nonlinear Stüssi function offers a good geometric approach to model the relationship $\Delta \sigma-N$ or $\Delta \in-N$ and the Weibull distribution is the most adequate to handle lifetime magnitudes as load cycles $N$. To show the application of the proposed model, simulated and experimental data of ASTM A969 steel are evaluated.
\end{abstract}

\section{Introduction}

In the behaviour of materials under cyclic loading three magnitudes are mainly considered: the strain range, the stress range and the number of load cycles. Several attempts have been done to describe the relationships between these variables, either in a deterministic or a probablistic way.

One the one hand, several models habe been proposed in [1-11] to describe the relationship between the stress range and the number of load cycles, see Table 1 .

On the other hand, to describe the relationship between the strain range and loading cycles, the models proposed by Coffin-Manson [12], Smith-Watson-Topper [13], Walker [14] and Castillo-Fernández-Canteli [15] are usually applied, see Table 2. However, in few cases a probablistic model has been proposed.

In [16] the author defines a general Cumulative Distribution Function (CDF) for the lifetime. This CDF depends on a two-parameter Weibull distribution whose parameters should be estimated. Afterwards, in the loglog scale, linear confidence intervals for the strain are obtained. Because of its linearity, this model is not suitable to perform estimations in Low Cycle Fatigue (LCF) or High Cycle Fatigue (HCF) regime.

In $[17,15]$ the authors proposed a model based on the RambergOsgood relationship and a three-parameter Weibull distribution. An application of this model is presented in $[18,19]$. Unfortunately, this model does not offer a suitable geometrical description of the strain in LCF regime.

In [20], the authors present a three-dimensional model to describe the relationship between stress, strain and load cycles. Since this deterministic model is based on the linear model of Basquin, its results are not suitable for estimations neither in LCF or HCF regime.

In [21] a linear regression model for statistical analysis of strain-life fatigue data is proposed. This model considers the LCF and the HCF separately and it defines a transition fatigue life as the point where the two linear regressions meet.

In [22] a strain-life curve based on the combination of HCF and LCF damage is presented. In [11] the authors propose a general fatigue model based on the Kohout-Věchet function. This model considers several fatigue damage parameters and one of its applications allows to depic strain-life curves.

At the present time, modelling the strain-life and stress-life curves is still a very important research topic in steel structures. For instance, several applications on riveted steel structures have been recently done by considering the models mentioned above, see [23-26].

In this paper the authors propose a model which describes the probabilistic relationships between strain range, stress range and loading cycles. This model is built by considering the following components:

-The nonlinear function proposed by Stüssi in [27,28] and applied by the authors to model the Wöhler curves in [29]

-The three-parameter Weibull distribution $W(a, b, c)$, see [30]

-The Ramberg-Osgood relationship considered in [31]

This paper is organized as follows. In Section 2 the Ramberg-Osgood relationship is presented and its inverse is calculated in order to express

\footnotetext{
* Corresponding author.

E-mail address: paul.toasa@kit.edu (P.D. Toasa Caiza).
} 
Table 1

Some models to represent $S-N$ curves.

\begin{tabular}{ll}
\hline Model & $S-N$ curves equation \\
\hline Basquin (1910) & $\log N=A-B \log \Delta \sigma ; \Delta \sigma \geqslant \Delta \sigma_{\infty}$ \\
Stromeyer (1914) & $\log N=A-B \log \left(\Delta \sigma-\Delta \sigma_{\infty}\right)$ \\
Palmgreen (1924) & $\Delta \sigma=b(N+B)^{-a}+\Delta \sigma_{\infty}$ \\
Bastenaire (1972) & $N=\frac{A}{\Delta \sigma-E} \exp [-C(\Delta \sigma-E)]-B$ \\
Ling \& Pan (1997) & $F=\sum_{i=1}^{n}\left\{\ln \sigma\left(S_{i}\right)+\frac{\left[\log N_{i}-\mu\left(S_{i}\right)\right]^{2}}{2 \sigma^{2}\left(S_{i}\right)}\right\}$ \\
Kohout \& Věchet (2001) & $\log \left(\frac{\Delta \sigma}{\Delta \sigma_{\infty}}\right)=\log \left(\frac{N+N_{1}}{N+N_{2}}\right)^{b}$ \\
Castillo et al. (2009) & $p=1-\exp \left\{-\left[\frac{(\log N-B)(\log \Delta \sigma-C)-a}{b}\right]^{c}\right\}$
\end{tabular}

Table 2

Some models to represent $\Delta \epsilon-N$ curves.

\begin{tabular}{ll}
\hline Model & $\Delta \epsilon-N$ curves equation \\
\hline Coffin-Manson (1954) & $\Delta \epsilon=2\left[\left(\frac{S_{e}}{E}\right)(2 N)^{b_{e}}+S_{p}(2 N)^{b_{p}}\right]$ \\
Smith-Watson-Topper (1970) & $\sigma_{\max } \epsilon_{a}=A_{1} N^{a_{1}}+A_{2} N^{a_{2}}$ \\
Walker (1970) & $\epsilon_{a}=\frac{\sigma_{f}^{\prime}}{E}\left(\frac{1-R}{2}\right)^{(1-\gamma)}(2 N)^{b}+\epsilon_{f}^{\prime}\left(\frac{1-R}{2}\right)^{c(1-\gamma) / b}(2 N)^{c}$ \\
Castillo et al. (2009) & $p=1-\exp \left\{-\left[\frac{(\log N-B)(\log \Delta \epsilon-C)-a}{b}\right]^{c}\right\}$
\end{tabular}

the stress range as function of the strain range. In Section 3 a function type Stüssi to express the strain range as function of the loading cycles is presented. Afterwards, a probabilistic model to express the quantile of this function is defined. In Section 4 a probabilistic function of the Ramberg-Osgood relationship is defined. In Section 5 the analytical results from the previous sections are applied on experimental data obtained from specimens made of ASTM A969 steel. Finally, in Section 6 the conclusions of this work are presented.

\section{The Ramberg-Osgood relationship and its inversion}

Before establishing the probabilistic realationship between strain range and the number of load cycles up to failure, it is necessary to find the inverse of the Ramberg-Osgood relationship.

According to Mostaghel [31], the Ramberg-Osgood relationship for the elastic and plastic regions can be denoted by

$\sigma_{a}=E \epsilon_{a}-\alpha \Delta \epsilon^{\beta}$ elastic,

$\epsilon_{a}=\frac{\sigma_{a}}{E}+\left(\frac{\sigma_{a}}{K^{\prime}}\right)^{\frac{1}{n^{\prime}}}$ plastic,

where

- $\sigma_{a}:$ stress cyclic amplitude

- $\epsilon_{a}$ :strain cyclic amplitude.

In the case of considering the stress range and strain range, the Ramberg-Osgood relationship can be described by

$\Delta \sigma=E \Delta \epsilon-2 \alpha\left(\frac{\Delta \epsilon}{2}\right)^{\beta}=\mathrm{RO}_{e l}(\Delta \epsilon)$ if $0 \leqslant \Delta \epsilon \leqslant \Delta \epsilon_{o}$,

$\Delta \epsilon=\frac{\Delta \sigma}{E}+\left(\frac{\Delta \sigma}{2^{\left(1-n^{\prime}\right)} K^{\prime}}\right)^{\frac{1}{n^{\prime}}}=\operatorname{RO}_{p l}^{-1}(\Delta \sigma)$ if $\Delta \epsilon \geqslant \Delta \epsilon_{o}$,

where

- E:modulus of elasticity

- $K^{\prime}$ :cyclic strength coefficient

- $n^{\prime}$ :cyclic strain hardening exponent

- $\Delta \epsilon_{o}$ :interface strain range

- $\alpha, \beta$ :geometrical parameters

- RO:Ramberg-Osgood relationshipFig. 1 shows the Ramberg-Osgood relationship according to Eqs. (3) and (4).

Manipulating the Eq. (4) leads to

$\Delta \sigma=2^{\left(1-n^{\prime}\right)} K^{\prime} \Delta \epsilon^{n^{\prime}}\left(1-\frac{\Delta \sigma}{E \Delta \epsilon}\right)^{n^{\prime}}$.

The power series of the last part in Eq. (5) is given by

$\left(1-\frac{\Delta \sigma}{E \Delta \epsilon}\right)^{n^{\prime}}=1-\frac{n^{\prime} \Delta \sigma}{E \Delta \epsilon}+\frac{\left(n^{\prime}-1\right) n^{\prime} \Delta \sigma^{2}}{2 E^{2} \Delta \epsilon^{2}}-\frac{\left(n^{\prime}-2\right)\left(n^{\prime}-1\right) n^{\prime} \Delta \sigma^{3}}{6 E^{3} \Delta \epsilon^{3}}+O\left(\Delta \sigma^{4}\right)$.

Taking only the terms up to 3rd order and replacing them in Eq. (5) leads to the 3rd degree polynomial

$P^{3}(\Delta \sigma)=A-B \Delta \sigma+C \Delta \sigma^{2}-D \Delta \sigma^{3}$,

where

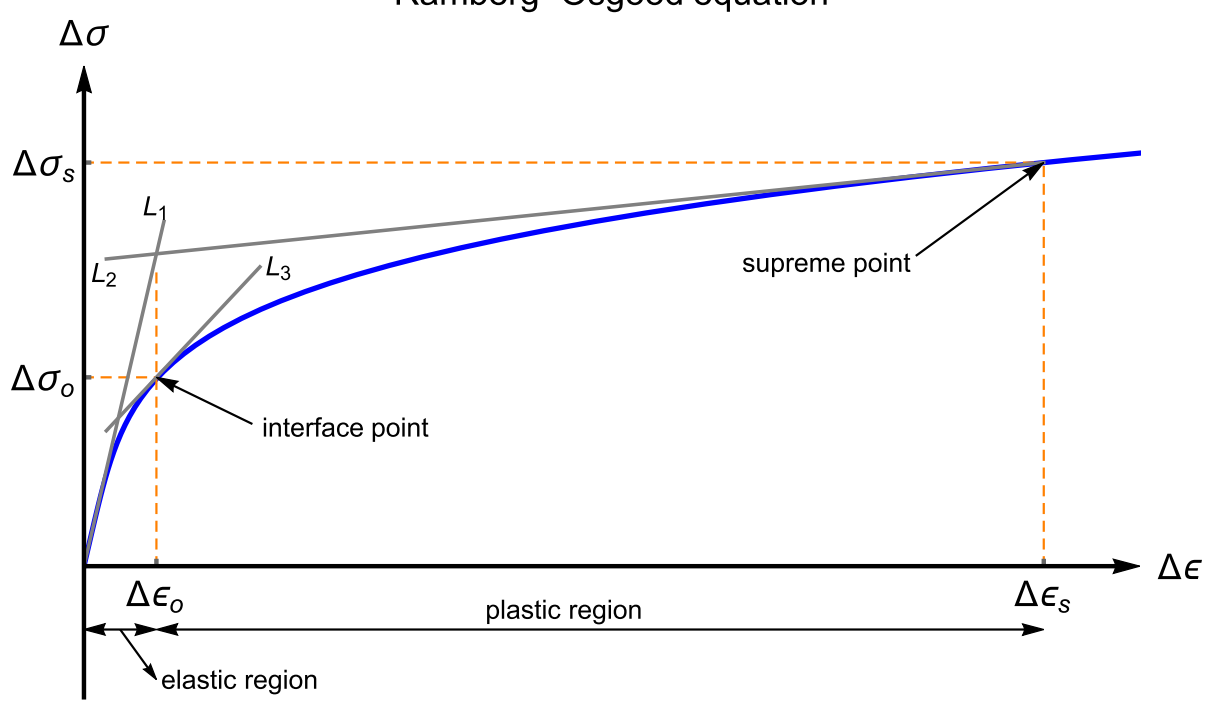

Fig. 1. Ramberg-Osgood relationship. The transition between the elastic and the plastic regions is given by the interface point $\left(\Delta \epsilon_{0}, \Delta \sigma_{0}\right)$. The upper limit of the plastic region is given by the supreme point $\left(\Delta \epsilon_{s}, \Delta \sigma_{s}\right)$. 
$A=2^{\left(1-n^{\prime}\right)} K^{\prime} \Delta \epsilon^{n^{\prime}}$,

$B=A \frac{n^{\prime}}{E \Delta \epsilon}$,

$C=A \frac{\left(n^{\prime}-1\right) n^{\prime}}{2 E^{2} \Delta \epsilon^{2}}$,

$D=A \cdot \frac{\left(n^{\prime}-2\right)\left(n^{\prime}-1\right) n^{\prime}}{6 E^{3} \Delta \epsilon^{3}}$.

Solving analytically the polynomial given in Eq. (7) leads to the Ramberg-Osgood relationship $R O_{p l}(\Delta \epsilon)$ given by

$\Delta \sigma=\frac{C}{3 D}$

$+\frac{2^{\frac{1}{3}}\left(-C^{2}+3 B D\right)}{3 D\left(-2 C^{3}+9 B C D-27 A D^{2}+\sqrt{4\left(-C^{2}+3 B D\right)^{3}+\left(-2 C^{3}+9 B C D-27 A D^{2}\right)^{2}}\right)^{\frac{1}{3}}}$

$-\frac{\left(-2 C^{3}+9 B C D-27 A D^{2}+\sqrt{4\left(-C^{2}+3 B D\right)^{3}+\left(-2 C^{3}+9 B C D-27 A D^{2}\right)^{2}}\right)^{\frac{1}{3}}}{3 \cdot 2 \frac{1}{3} D}$.

For simplicity, this solution will be denoted by

$\Delta \sigma=\mathrm{RO}_{p l}(\Delta \epsilon)$ if $\Delta \epsilon \geqslant \Delta \epsilon_{0}$.

Thus, the Ramberg-Osgood relationship is defined explicitily by Eqs. (3) and (8).

From now on, if no difference between the elastic and plastic region should be remarked, the general and explicit Ramberg-Osgood relationship will be denoted as

$\Delta \sigma=\operatorname{RO}(\Delta \epsilon)$.

Within this paper, the authors consider the 3rd order aproximation is enough for the purpose of this work. A 4th order approximation is presented in [31], and an alternative method to invert the Ramberg-Osgood relationship can be found in [32].

\subsection{Finding the interface point $\left(\Delta \epsilon_{o}, \Delta \sigma_{o}\right)$}

In order to establish the strain range domains of Eqs. (3) and (8), it is necessary to find the interface point $\left(\Delta \epsilon_{o}, \Delta \sigma_{0}\right)$, which separates the elastic and the plastic regions, see Fig. 1.

Since the interface point lies in the intersection of lines $L_{1}$ and $L_{2}$, the task is done if the equations of the lines are established, see Fig. 1.

It is well known that the equation of line $L_{1}$ is given by

$\Delta \sigma=E \Delta \epsilon$

From now on, it is assumed that a large enough strain range $\Delta \epsilon_{s}$ known as supreme strain range is given. Then, by applying Eq. (8) its corresponding supreme stress range $\Delta \sigma_{s}$ can be calculated by

$\Delta \sigma_{s}=\mathrm{RO}_{p l}\left(\Delta \epsilon_{s}\right)$.

Afterwards, it is necessary to calculate the slope $E_{s}$ of line $L_{2}$. For this purpose, the derivative of Eq. (4)

$\frac{\mathrm{d} \Delta \epsilon}{\mathrm{d} \Delta \sigma}=\frac{1}{E}+\frac{1}{n^{\prime}} \frac{\Delta \sigma^{\left(\frac{1}{n^{\prime}}-1\right)}}{2^{\left(\frac{1}{n^{\prime}}-1\right)} K^{\prime \frac{1}{n^{\prime}}}}$,

has to be considered.

From elementary calculus, the condition $\frac{\mathrm{d} \Delta \epsilon}{\mathrm{d} \Delta \sigma}\left(\Delta \sigma_{S}\right)=\frac{1}{E_{S}}$ has to be satisfied. Then, the slope $E_{s}$ of line $L_{2}$ is given by

$E_{S}=\frac{E}{1+\frac{E \Delta \sigma_{S}^{\left(\frac{1}{n^{\prime}}-1\right)}}{n^{\prime 2}\left(\frac{1}{n^{\prime}}-1\right) K^{\prime} \frac{1}{n}}}$.

Thus, equation of line $L_{2}$ is defined by

$\Delta \sigma=E_{S} \Delta \epsilon-E_{S} \Delta \epsilon_{s}+\Delta \sigma_{s}$.

As mentioned before, considering the intersection of the two lines given by Eqs. (10) and (14) leads to the interface strain range

$\Delta \epsilon_{o}=\frac{\Delta \sigma_{s}-E_{s} \Delta \epsilon_{s}}{E-E_{s}}$, and then by applying the equation $\mathrm{RO}_{p l}$, its corresponding interface stress range is obtained by

$\Delta \sigma_{o}=\mathrm{RO}_{p l}\left(\Delta \epsilon_{o}\right)$.

\subsection{Calculating the geometrical parameters $\alpha$ and $\beta$}

The parameters $\alpha$ and $\beta$ define the Ramberg-Osgood relationship in the elastic region, see Eq. (3). These parameters can be calculated by the following considerations.

First, it is necessary to calculate the slope $E_{0}$ of line $L_{3}$. In other words, the condition $\frac{\mathrm{d} \Delta \epsilon}{\mathrm{d} \Delta \sigma}\left(\Delta \sigma_{o}\right)=\frac{1}{E_{o}}$, has to be satisfied. Then the slope of line $L_{3}$ is given by

$E_{o}=\frac{E}{1+\frac{E \Delta \sigma_{0}^{\left(\frac{1}{n^{\prime}}-1\right)}}{n^{\prime} 2\left(\frac{1}{n^{\prime}}-1\right)} K^{\prime} \frac{1}{n^{\prime}}}$.

Since, the interface point $\left(\Delta \epsilon_{o}, \Delta \sigma_{o}\right)$ belongs also to the curve $R O_{e l}$ given by Eq. (3), it leads to

$\alpha=\frac{2^{(\beta-1)} E \Delta \epsilon_{o}-\Delta \sigma_{o}}{\Delta \epsilon_{o}^{\beta}}$.

Now consider the derivative of Eq. (3) which is given by

$\frac{\mathrm{d} \Delta \sigma}{\mathrm{d} \Delta \epsilon}=E-\alpha \beta\left(\frac{\Delta \epsilon}{2}\right)^{\beta-1}$.

Evaluating this derivative in the interface strain range $\Delta \epsilon_{o}$ leads to the slope $E_{o}$ of line $L_{3}$. It means, that the condition $\frac{\mathrm{d} \Delta \sigma}{\mathrm{d} \Delta \epsilon}\left(\epsilon_{o}\right)=E_{o}$, has to be satisfied.

Then

$\alpha=\frac{2^{\beta-1}\left(E-E_{o}\right)}{\beta \Delta \epsilon_{o}^{\beta-1}}$ by

Afterwards, equalizing Eqs. (18) and (20) leads to the parameter $\beta$

$\beta=\frac{\Delta \epsilon_{o}\left(E-E_{o}\right)}{E \Delta \epsilon_{o}-\Delta \sigma_{o}}$.

\subsection{Application on simulated data}

In order to prove the suitability of the inversion method of the Ramberg-Osgood relationship, simulated data were generated.

The simulation was performed according to Eq. (2) and by considering a stress ratio $R=-1$ and the properties of ASTM A969 hot dipped galvanized sheet steel given in Table 3 .

ASTM A969 is a cold-rolled, low carbon, extra deep drawing steel (EDDS), which usually is used in the automotive industry, see $[16,33]$.

The calculations corresponding to the simulation were performed with Mathematica 12.0.

The results corresponding to the coordinates of the interface point

Table 3

Material properties.

\begin{tabular}{llrl}
\hline \multicolumn{4}{c}{ Material properties - ASTM A969 } \\
\hline Modulus of elasticity & $E$ & 206824 & [MPa] \\
Cyclic strength coefficient & $K^{\prime}$ & 800,57 & \\
Cyclic strain hardening exponent & $n^{\prime}$ & 0,2261 & \\
Yield strength & $R_{e l}$ & 164 & {$[\mathrm{MPa}]$} \\
Tensile strength & $R_{m}$ & 297 & {$[\mathrm{MPa}]$} \\
Elastic coefficient & $S_{e}$ & 669,32 & \\
Elastic exponent & $b_{e}$ & $-0,1174$ & \\
Plastic coefficient & $S_{p}$ & 0,299 & \\
Plastic exponent & $b_{p}$ & $-0,4844$ & \\
Fatigue limit & $\Delta \sigma_{\infty}$ & 122,84 & [MPa] \\
& & & \\
\hline
\end{tabular}


Table 4

Parameters of the Ramberg-Osgood relationship.

\begin{tabular}{llr}
\hline & Interface Point & \\
\hline$\Delta \epsilon_{0}$ & 0,00267525 & {$[-]$} \\
$\Delta \sigma_{0}$ & 302,033 & {$[\mathrm{MPa}]$} \\
\hline & Geometrical parameters & \\
$\alpha$ & $1,27516 \cdot 10^{7}$ & \\
$\beta$ & 1,74218 & \\
\hline
\end{tabular}

and to the values of the geometrical parameters of Eq. (3) are shown in Table 4.

A plot of a simulated Ramberg-Osgood relationship and its corresponding data are shown in Fig. 2.

\section{Consideration of the strain range from the Ramberg-Osgood relationship in the Stüssi model}

The interest in fatigue design is obtaining a reliable probablistic model to estimate the fatigue behaviour of a structure. For this purpose, a suitable model has to be developed. This model has to consider: a). a geometrical function which describes properly the relation between the stress range and the applicable load cycles or between the strain range and the load cycles and b). a statistical distribution for the lifetime. In this paper, the model proposed by the authors in [29], which is based on the Stüssi function $[27,28]$ and a three-parameter Weibull distribution $W(a, b, c)$ is considered.

\subsection{The Stuissi function for the strain range}

Consider the Stüssi function for the stress range given by

$\Delta \sigma=\frac{R_{m}(1-R)+\alpha N^{\beta} \Delta \sigma_{\infty}}{1+\alpha N^{\beta}}=\mathrm{S}(N)$,

where

- $\Delta \sigma$ :stress range during the fatigue test

- $N$ :number of load cycles up to failure or up to end of the test

- $R_{m}$ :ultimate tensile strength

- $\Delta \sigma_{\infty}$ :fatigue limit ${ }^{1}$

- $\alpha, \beta$ :geometrical parameters

- $R$ :stress ratio

- $S$ :Stüssi function.

The method to estimate the geometrical parameters is described in [29]. Be aware that the geometrical parameters $\alpha$ and $\beta$ from Eq. (22) are different than the parameters from Eq. (3).

Combining the Stüssi function given by Eq. (22) with the inverse of the Ramberg-Osgood relationship given by Eqs. (3) and (8), a new Stüssi function for the strain range as function of the loading cycles given by

$\Delta \epsilon=\mathrm{RO}^{-1}\left(\frac{R_{m}(1-R)+\alpha N^{\beta} \Delta \sigma_{\infty}}{1+\alpha N^{\beta}}\right)=\mathrm{RO}^{-1}(\mathrm{~S}(N))$

is obtained.

Moreover, this function describes clearly the asymptotic behaviour regarding the ultimate tensile strength $R_{m}$ in the plastic region and the fatigue limit $\Delta \sigma_{\infty}$ in the elastic region by.

- $\lim _{N \rightarrow 0} \Delta \epsilon=\mathrm{RO}^{-1}\left(R_{m}(1-R)\right)$

- $\lim _{N \rightarrow \infty} \Delta \epsilon=\mathrm{RO}^{-1}\left(\Delta \sigma_{\infty}\right)$.

${ }^{1}$ The existence of the fatigue limit is still an open debate, see for example $[34,35]$.
Figs. 3 shows the $\Delta \in-N$ curve given by the Stüssi function in the $\log -\log$ scale.

\subsection{Probabilistic model}

In [29] a probabilistic model based on the Stüssi function and the Weibull distribution was proposed. For this model it was considered that $\Delta \sigma-S(N)$ is a random variable which follows a Weibull distribution $W(a, b, c)$. Under these considerations, and using the notation of Eq. (23) the probabilistic model is defined by

$p=1-\exp \left\{-\left[\frac{\Delta \sigma-\mathrm{S}(N)-a}{b}\right]^{c}\right\}$,

where

- $p$ :probability of failure

- $a \in \mathbb{R}:$ Weibull location parameter

- $b>0$ :Weibull scale parameter

- $c>0$ :Weibull shape parameter

Replacing the general Ramberg-Osgood relationship given by Eq. (9) in Eq. (24), leads to a Stüssi probabilistic function to model the $\Delta \in-N$ curves in the elastic and plastic regions given by

$p=1-\exp \left\{-\left[\frac{\mathrm{RO}(\Delta \epsilon)-\mathrm{S}(N)-a}{b}\right]^{c}\right\}$.

The model given by Eq. (25) depends on two geometrical parameters $\alpha, \beta$ of Eq. (22) and on three Weibull parameters $a, b$ and $c$. The geometrical parameters can be estimated by a linear regression, see [29] and the Weibull parameters can be estimated by applying the PWM method, see [36].

Once all parameters have been estimated, the $\Delta \epsilon-N$ curves can be depicted.

\subsection{Application on simulated data}

As in Section 2.3, simulated data corresponding to ASTM A969 hot dipped galvanized sheet steel are considered. Moreover, the Stüssi quantile will be compared with the well known Coffin-Manson equation (CM), which relates the strain range and the loading cycles and is given by

$\Delta \epsilon=2\left[\left(\frac{S_{e}}{E}\right)(2 N)^{b_{e}}+S_{p}(2 N)^{b_{p}}\right]$,

where

- $S_{e}$ :elastic coefficient

- E:modulus of elasticity

- $b_{e}$ :elastic exponent

- $S_{p}$ :plastic coefficient

- $b_{p}$ :plastic exponent.

The geometrical parameters of the Stüssi function given by Eq. (22) are estimated by applying the method proposed in [29], see Table 5 .

The Weibull parameters estimated by applying the method proposed in [36] are shown in Table 6.

A graphical representation of the $\Delta \in-N$ curves given by Eq. (25) is shown in Fig. 4. In this Figure, it can be seen that the $50 \%$ quantile of the $\Delta \epsilon-N$ curve and the curve given by the Coffin-Manson equation have a very similar geometry between $10^{4}$ and $10^{7}$ load cycles. The quantiles given by Eq. (25) seem to be a reliable probabilistic alternative to the Coffin-Manson equation. 


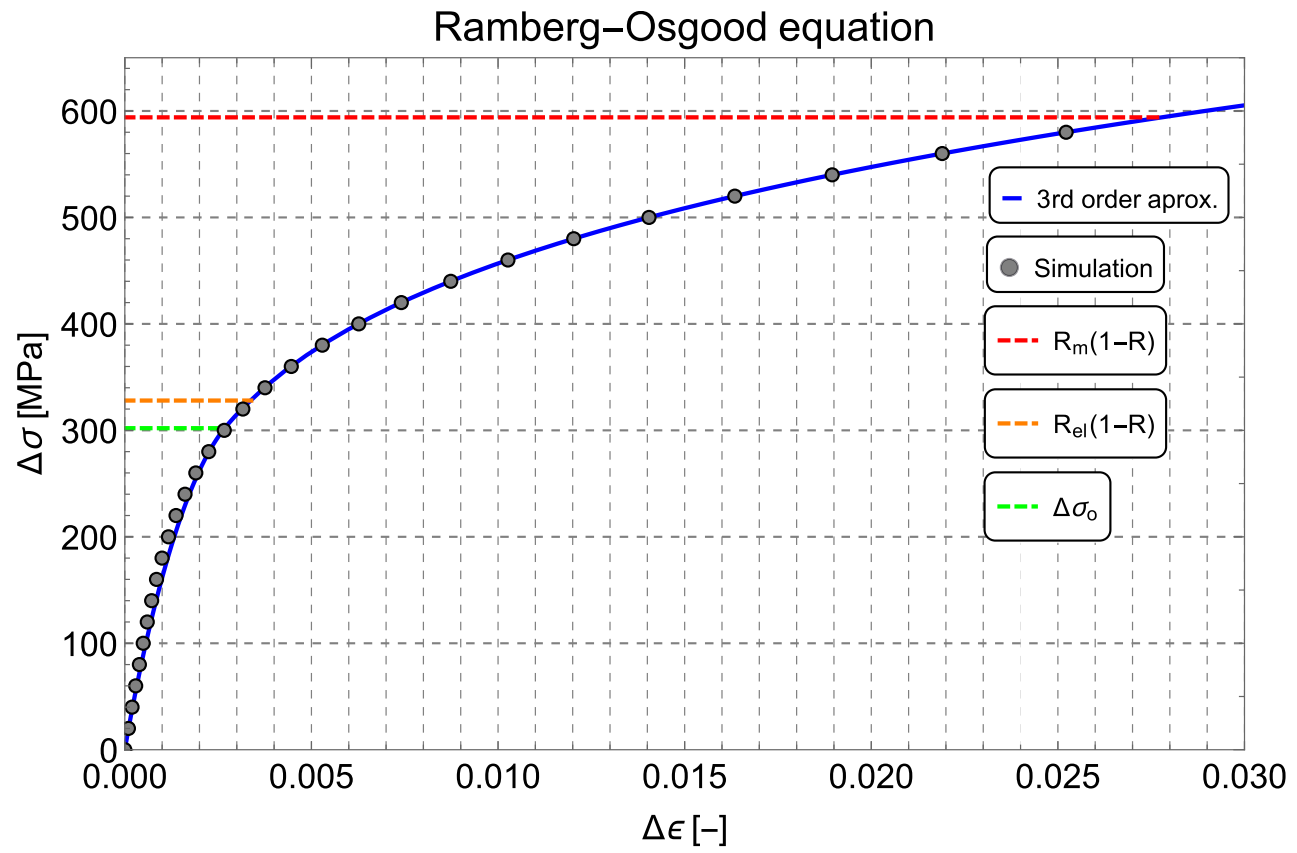

Fig. 2. Ramberg-Osgood relationship and its corresponding simulated data. Supreme strain $\Delta \epsilon_{s}=0$, 06 . The stress ratio of the fatigue tests is $R=-1$.

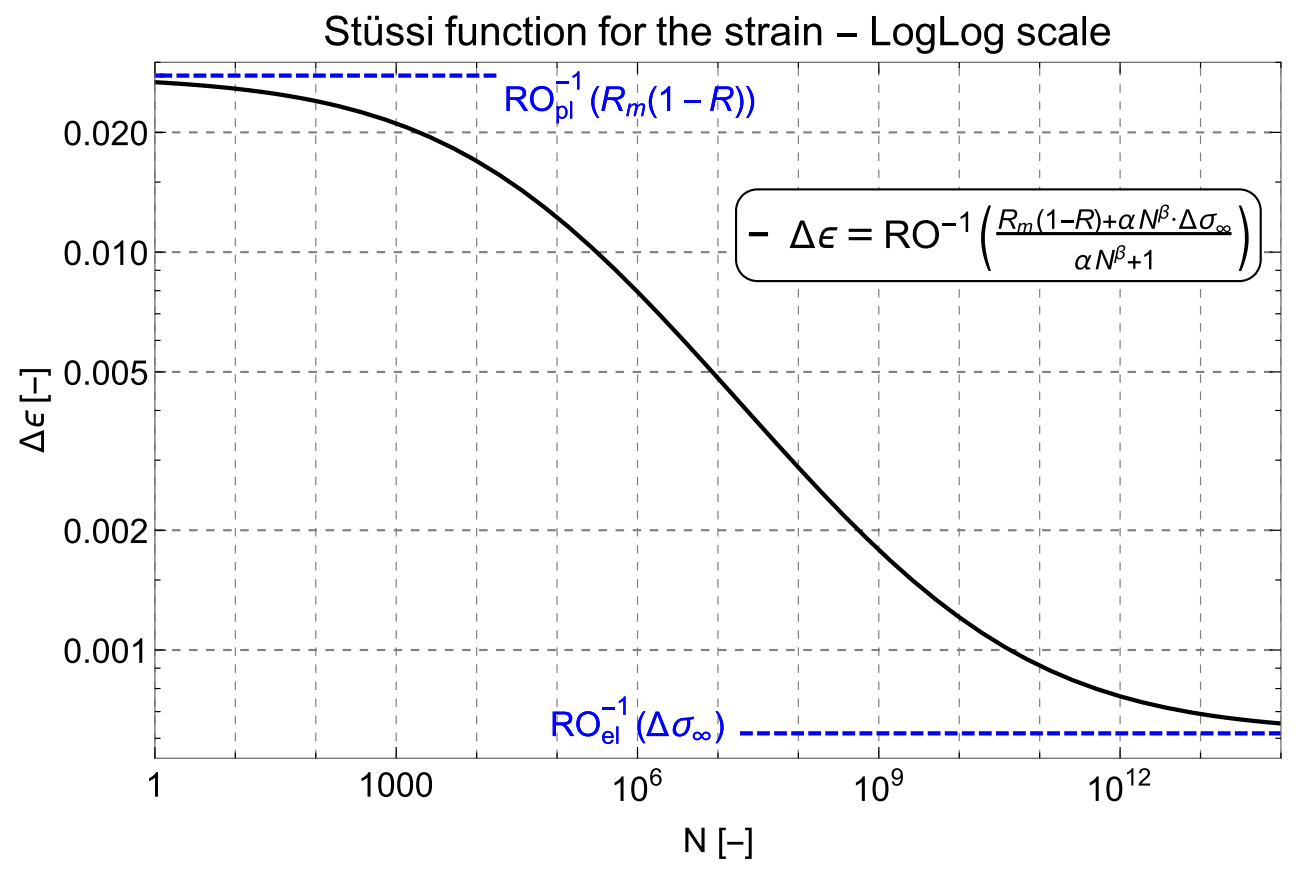

Fig. 3. Stüssi function for the strain range.

\section{Probablistic Ramberg-Osgood relationship}

Based on the Stüssi probabilistic functions proposed in the previous section, a probablistic formulation for the Ramberg-Osgood relationship can be defined.
On the one hand, in the probabilistic Stiussi model given by the Eq. (24), the considered random variable was $\Delta \sigma-\mathrm{S}(N)$.

On the other hand, from the Ramberg-Osgood relationship and Stussi function, given by Eq. (9) and Eq. (22) respectively, it can be established that $\mathrm{S}(N)=\mathrm{RO}(\Delta \epsilon)$.
Table 5

Parameters estimation from the Stüssi function. Simulated data.

\begin{tabular}{cc}
\hline \multicolumn{3}{c}{ Geometrical parameters } \\
\hline$\alpha$ & 0,03274 \\
$\beta$ & 0,32457
\end{tabular}

Table 6

Weibull parameters estimation of the probabilistic Stüssi function. Simulated data.

\begin{tabular}{lr}
\hline \multicolumn{3}{c}{ Weibull parameters } \\
\hline$a$ & $-25,7662$ \\
$b$ & 28,8251 \\
$c$ & 3,2157
\end{tabular}




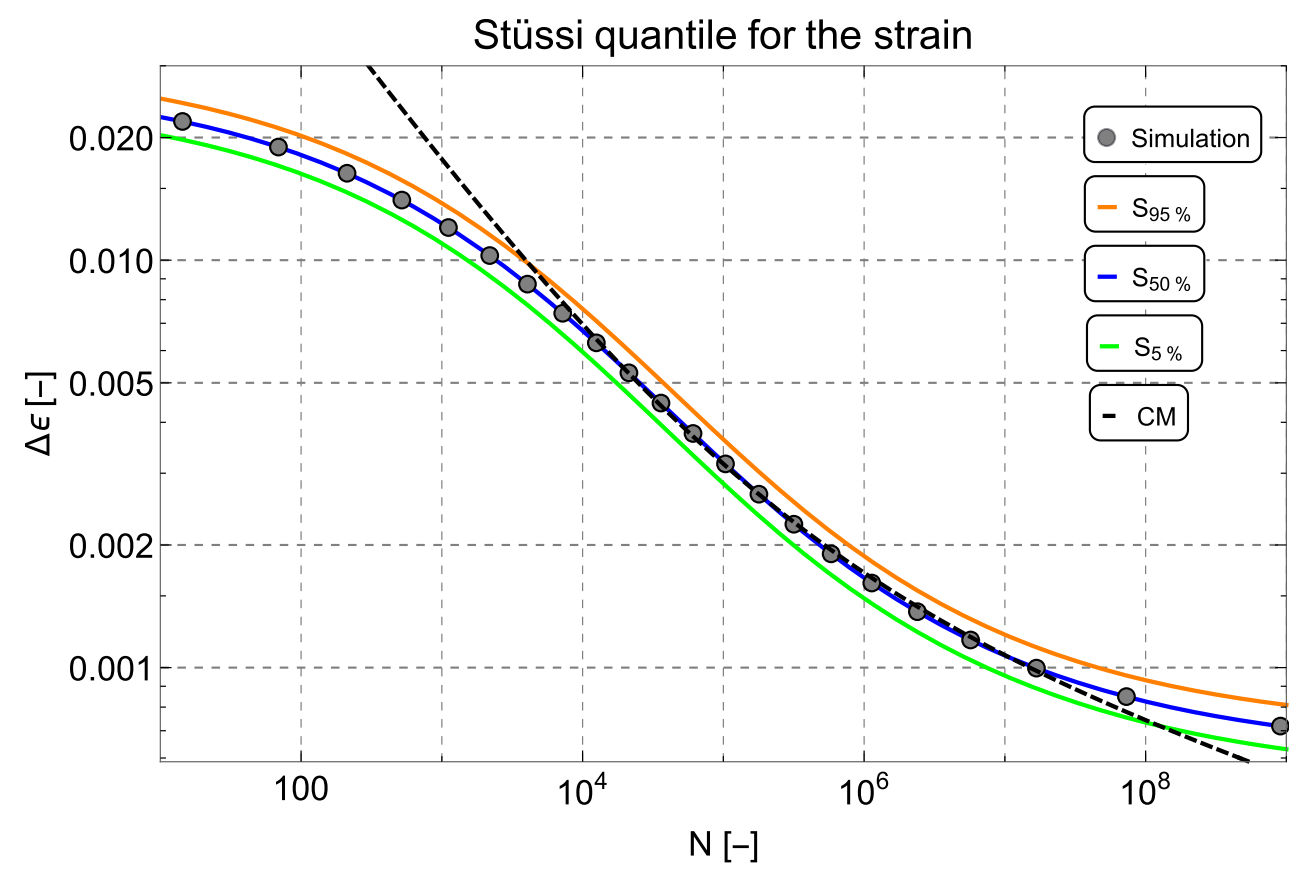

Fig. 4. $\Delta \in-N$ curves based on the Stüssi model. The plotted curves correspond to a probability of $5 \%, 50 \%$ and $95 \%$.

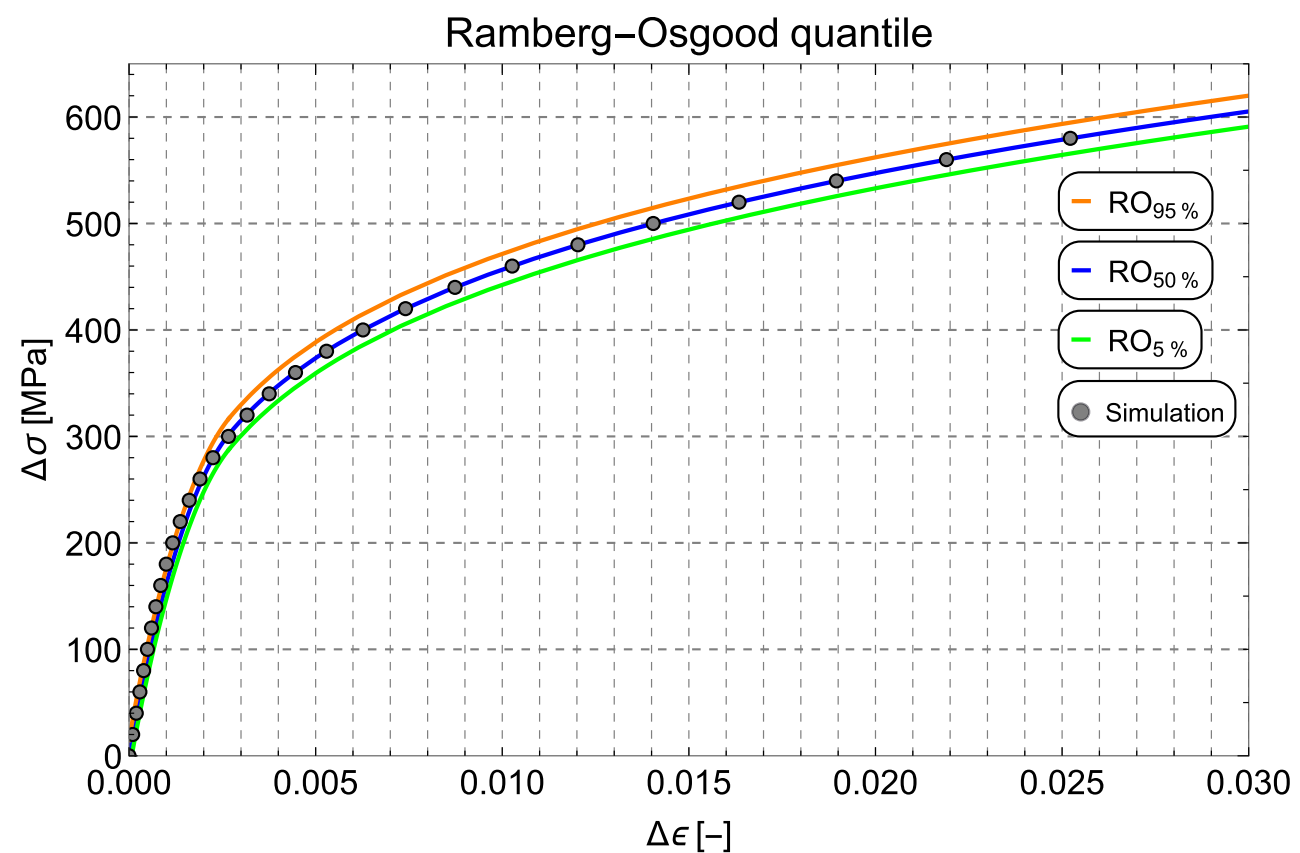

Fig. 5. Quantile of the Ramberg-Osgood relationship based on the Stüssi model. The plotted curves correspond to a probability of $5 \%$, $50 \%$ and $95 \%$.

Table 7

Parameters estimation from the Stüssi function. Experimental data.

\begin{tabular}{cc}
\hline \multicolumn{3}{c}{ Geometrical parameters } \\
\hline$\alpha$ & 0,02262 \\
$\beta$ & 0,35543
\end{tabular}

For these reasons, it seems plausible to consider an equivalent random variable given by $\Delta \sigma-\mathrm{RO}(\Delta \epsilon)$. Since this variable is only obtained by replacing equations, it should also follow the same threeparameter Weibull distribution $W(a, b, c)$.
Table 8

Weibull parameters estimation of the probabilistic Stüssi function. Experimental data.

\begin{tabular}{lr}
\hline \multicolumn{3}{c}{ Weibull parameters } \\
\hline$a$ & $-40,9495$ \\
$b$ & 45,3065 \\
$c$ & 2,52388
\end{tabular}

Under these considerations a probablistic function for the Ramberg-Osgood relationship can be defined as follows.

$p=1-\exp \left\{-\left[\frac{\Delta \sigma-\mathrm{RO}(\Delta \epsilon)-a}{b}\right]^{c}\right\}$. 


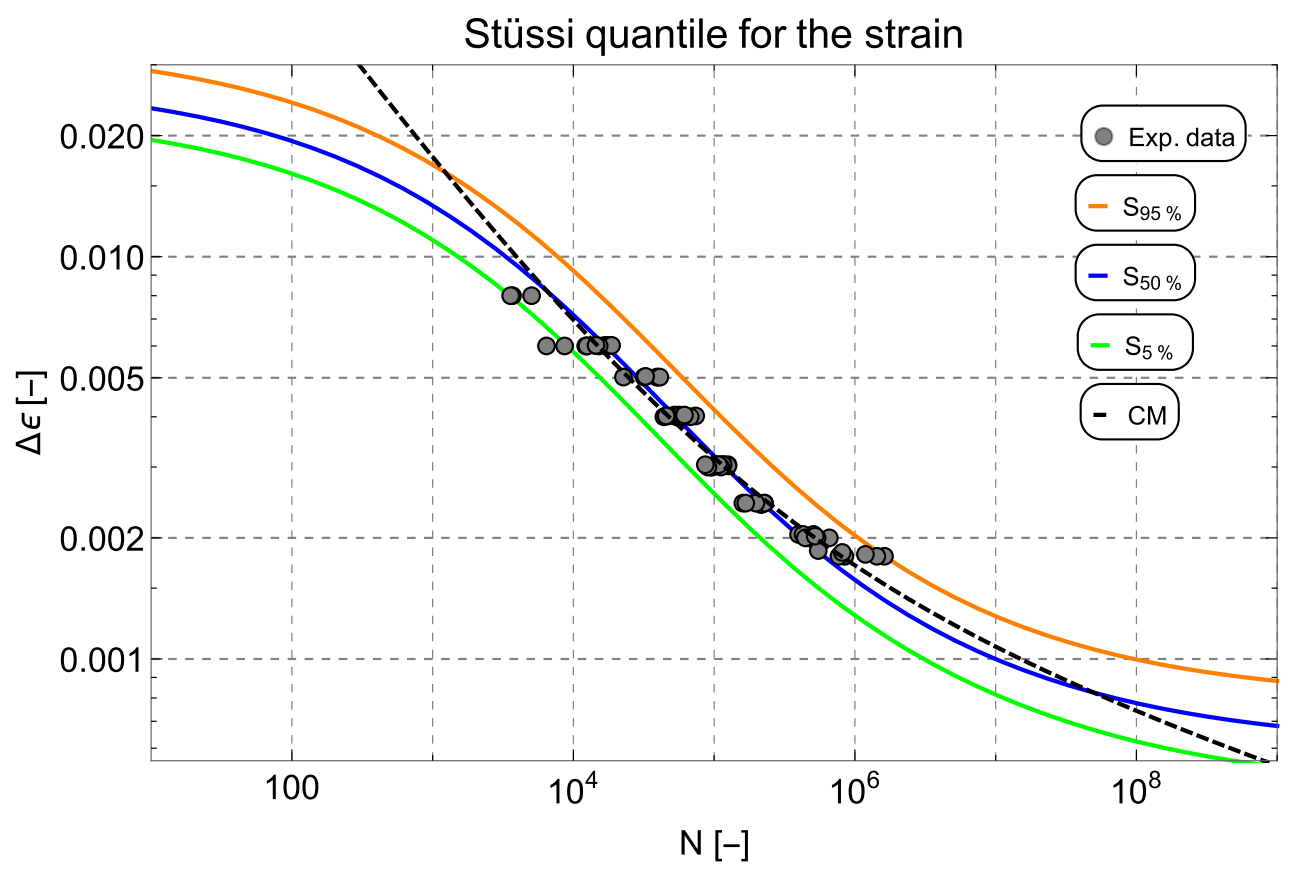

Fig. 6. Stüssi quantile for the strain range. The plotted curves correspond to a probability of 5\%, 50\% and $95 \%$.

\subsection{Application on simulated data}

As in the Sections 2.3 and 3.3, the same simulated data are considered to evaluate the model.

A graphical representation of the quantile of the Ramberg-Osgood relationship given by Eq. (27) is shown in Fig. 5.

\section{Application on specimens made of ASTM A969 steel}

The application presented in this section is based on the experimental data considered in [16]. These data were provided by the Steel Market Development Institute (SMDI) ${ }^{2}$.

\subsection{Material and specimens}

Sixty-nine specimens made of hot dipped galvanized sheet steel ASTM A969 were tested. The main properties of the material are described in Table 3.

\subsection{Fatigue tests}

The specimens were tested under a constant stress range with a tringular wave form and a stress ratio $R=-1$. The tests were terminated when the tensile load was dropped by $50 \%$ from the maximum load or the test was a runout up to $10^{7}$ loading cycles. The corresponding experimental data provide the stress range, strain range and loading cycles.

\subsection{The Stüssi model for the strain range}

In order to plot the corresponding $\Delta \epsilon-N$ quantile, some steps should be done. First, it is necessary to find the inverse of the Ramberg-Osgood relationship. This step is accomplished by estimating of the geometrical parameters $\alpha$ and $\beta$ from Eq. (3). Since the inversion of the Ramberg-Osgood relationship does not depend on the experimental data but

\footnotetext{
${ }^{2}$ IF_DDQ_HDG70G_Strain_Life_Fatigue.xls
}

on the material properties shown in Table 3, this step is already done, see Table 4.

Aftwerwards, the geometrical parameters of Eq. (22) are estimated by applying the method proposed in [29]. The corresponding estimations are shown in Table 7.

Once the geometrical parameters have been estimated, it is possible to estimate the Weibull parameters of Eq. (25). The method of the PWMs has been applied for this task, see [36]. For this case the estimations of the Weibull parameters are shown in Table 8.

The $\Delta \epsilon-N$ curves corresponding to a probablity of $5 \%, 50 \%$ and 95\% are shown in Fig. 6.

\subsection{The Stüssi model for the Ramberg-Osgood relationship}

As it was explained in Section 4, based on the experimental data and applying Eq. (27), it is possible also to depict quantile of the Ramberg-Osgood relationship.

The quantiles of the Ramberg-Osgood relationship corresponding to a probablity of 5\%,50\% and $95 \%$ are shown in Fig. 7 .

\subsection{The Stüssi model for the stress range}

Finally, by applying the Stüssi model for the stress range given by Eq. (24) the corresponding $\Delta \sigma-N$ quantile can be depicted.

The quantiles of the $\Delta \sigma-N$ curve, corresponding to a probablity of $5 \%, 50 \%$ and $95 \%$ are shown in Fig. 8 .

\section{Conclusions and recommendations}

As it has been shown in the previous sections, a new statistical proposal for modelling the $\Delta \sigma-N, \Delta \epsilon-N$ curves and the Ramberg-Osgood relationship has been made by combining the Stüssi function and the three-parameter Weibull distribution $W(a, b, c)$. Moreover, this proposal allows to obtain estimations of the fatigue lifetime of a structure either in LCF and HCF. This fact represents an advantage compared to the Basquin model which is considered in the official standards.

On the one hand, the Stüssi function offers a good geometric 


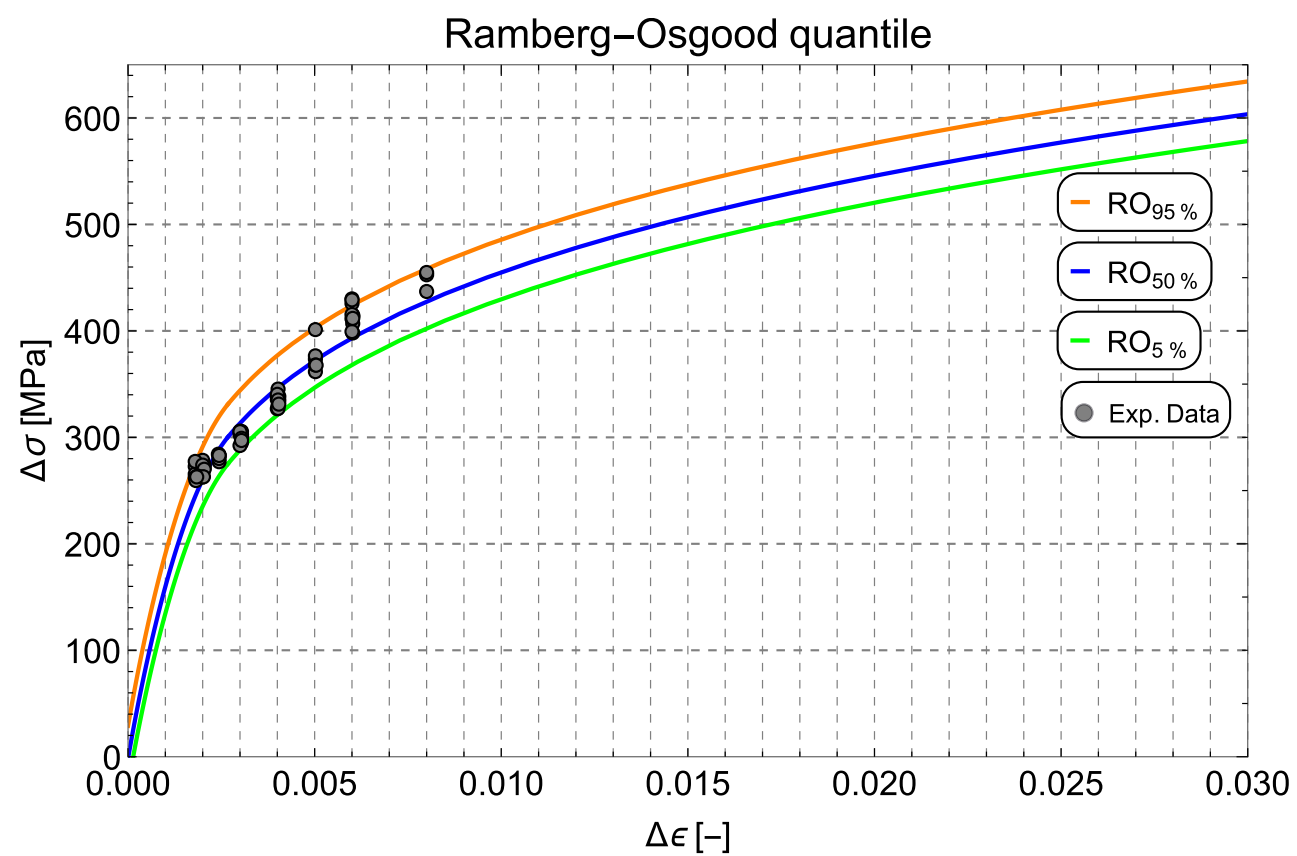

Fig. 7. Quantile of the Ramberg-Osgood relationship. The plotted curves correspond to a probability of 5\%, 50\% and $95 \%$.

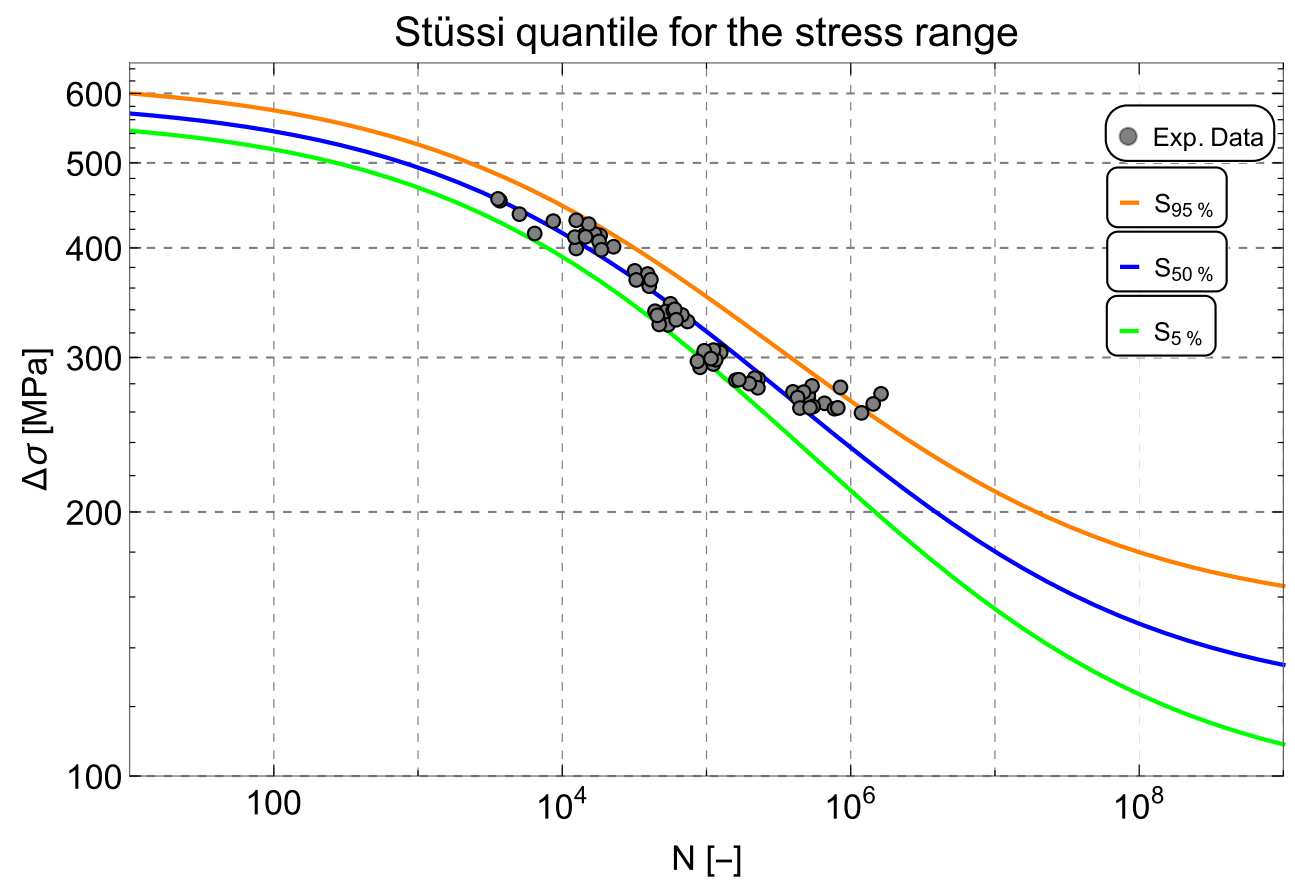

Fig. 8. Stüssi quantile for the stress range. The plotted curves correspond to a probability of $5 \%, 50 \%$ and $95 \%$.

description of the $\Delta \sigma-N$ and $\Delta \in-N$ curves. In fact, it describes properly their asymptotic characteristics given by the ultimate tensile strength and by the fatigue limit.

In LCF this function is suitable to estimate the fatigue lifetime, since it converges smoothly to the ultimate tensile strength, while in HCF it converges to the fatigue limit.

On the other hand, since the number of load cycles can be considered as random lifetime variable, the three-parameter Weibull distribution $W(a, b, c)$ is the adequate one to describe this magnitude.

In order to obtain the best results applying the method proposed in this work, the suggestions made in [29] can be taken into account for the planning of fatigue tests.

Regarding the lifetime estimation there are still a lot of questions and concerns, which have to be considered in future investigations. One of them is making estimations in the ultra low cycle fatigue (ULCF) regime where the plastic behaviour prevails.

The authors want to express their gratitude to the German Research Foundation $\mathrm{DFG}^{3}$ for the funds granted to perform the research in fatigue of steel structures.

\footnotetext{
${ }^{3}$ Deutsche Forschungsgemeinschaft.
} 


\section{Declaration of Competing Interest}

None.

\section{References}

[1] Bastenaire F. New method for the statistical evaluation of constant stress amplitude fatigue-test results. Probab Aspects Fatigue STP 1972(511):3-28.

[2] Ling J, Pan J. A maximum likelihood method for estimating P-S-N curves. Int J Fatigue 1997;19(5):415-9. https://doi.org/10.1016/S0142-1123(97)00037-6.

[3] Marquis G, Huther M, Galtier A. Guidance for the application of the best practice guide on statistical analysis of fatigue data, IIW-WG1-132-08.

[4] Pascual F, Meeker W. Estimating fatigue curves with the random fatigue-limit model. Technometrics 1999;41(4):277-90.

[5] Lorén S, Lundström M. Modelling curved S-N curves. Fatigue Fract Eng Mater Struct 2005;28(5):437-43. https://doi.org/10.1111/j.1460-2695.2005.00876.x.

[6] Schijve J. Fatigue of structures and materials. Springer Verlag; 2009.

[7] Stromeyer C. The determination of fatigue limits under alternating stress conditions. Proc Roy Soc Lond 1914;90(620):411-25. https://doi.org/10.1098/rspa.1914. 0066.

[8] Kohout J, Věchet S. A new function for fatigue curves characterization and its multiple merits. Int J Fatigue 2001;23(2):175-83. https://doi.org/10.1016/S01421123(00)00082-7.

[9] Bomas H, Burkart K, Zoch H-W. Evaluation of S-N curves with more than one failure mode. Int J Fatigue 2011;33:19-22. https://doi.org/10.1016/j.ijfatigue.2010.04. 010 .

[10] Paolino DS, Chiandussi G, Rossetto M. A unified statistical model for S-N fatigue curves: probabilistic definition. Fatigue Fract Eng Mater Struct 2012;36(3):187-201. https://doi.org/10.1111/j.1460-2695.2012.01711.x.

[11] Correia J, Raposo P, Muniz-Calvente M, Blasón S, Lesiuk G, Jesus AD, et al. A generalization of the fatigue Kohout-Věchet model for several fatigue damage parameters. Eng Fract Mech. https://doi.org/10.1016/j.engfracmech.2017.06.009.

[12] Coffin L. A study of the effects of cyclic thermal stresses on a ductile metal. In: Transactions of the ASME, Vol. 76; 1954. p. 931-50.

[13] Smith K, Topper T, Watson P. A stress-strain function for the fatigue of metals. J Mater 1970;5:767-78.

[14] Walker K. The effect of stress ratio during crack propagation and fatigue for 2024-t3 and 7075-t6 aluminum. In: Effects of environment and complex load history on fatigue life. ASTM Int; 1970. p. 1-14. https://doi.org/10.1520/ STP32032S

[15] Castillo E, Fernández-Canteli A. A unified statistical methodology for modeling fatigue damage. Springer Verlag; 2009.

[16] Harlow GD. Low cycle fatigue: probability and statistical modeling of fatigue life In: ASME 2014 Pressure vessels and piping conference, Vol. 6B: Materials and Fabrication, ASME; 2014. https://doi.org/10.1115/PVP2014-28114.

[17] Fernández-Canteli A, Castillo E, Pinto H, López-Aenlle M. Estimating the S-N field from strain-lifetime curves. Strain 2011;47:e93-7. https://doi.org/10.1111/j.14751305.2008.00548.x

[18] Jesus AMD, Pinto H, Fernández-Canteli A, Castillo E, Correia JA. Fatigue assessment of a riveted shear splice based on a probabilistic model. Int J Fatigue 2010;32(2):453-62. https://doi.org/10.1016/j.ijfatigue.2009.09.004.

[19] Apetre N, Arcari A, Dowling N, Iyyer N, Phan N. Probabilistic model of mean stress effects in strain-life fatigue. Proc Eng 2015;114: 538-45, iCSI 2015 The 1st International Conference on Structural Integrity Funchal, Madeira, Portugal 1st to 4th September, 2015. doi: 10.1016/j.proeng.2015.08.103. URL: http://www.sciencedirect.com/science/article/pii/S1877705815017427.

[20] Niesłony A, el Dsoki C, Kaufmann H, Krug P. New method for evaluation of the Manson-Coffin-Basquin and Ramberg-Osgood equations with respect to compatibility. Int J Fatigue 2008;30(10):1967-77. https://doi.org/10.1016/j.ijfatigue 2008.01.012.

[21] Williams C, Lee Y-L, Rilly J. A practical method for statistical analysis of strain-life fatigue data. Int J Fatigue 2003;25(5):427-36. https://doi.org/10.1016/S01421123(02)00119-6.

[22] Karunananda K, Ohga M, Dissanayake R, Siriwardane S, Chun P-J. New combined high and low-cycle fatigue model to estimate life of steel bridges considering interaction of high and low amplitudes loadings. Adv Struct Eng 2012;15:287-302. https://doi.org/10.1260/1369-4332.15.2.287.

[23] Leonetti D, Maljaars J, Snijder HB. Fatigue life prediction of hot-riveted shear connections using system reliability. Eng Struct 2019;186:471-83. https://doi.org/ 10.1016/j.engstruct.2019.02.047.

[24] da Silva AL, Correia JA, de Jesus AM, Figueiredo MA, Pedrosa BA, Fernandes AA, et al. Fatigue characterization of a beam-to-column riveted joint. Eng Fail Anal 2019;103:95-123. https://doi.org/10.1016/j.engfailanal.2019.04.073.

[25] Niederwanger A, Ladinek M, Lener G. Strain-life fatigue assessment of scanned weld geometries considering notch effects. Eng Struct 2019;201:109774 https://doi.org/ 10.1016/j.engstruct.2019.109774.

[26] Liu Z, Correia J, Carvalho H, Mourão A, de Jesus A, Calçada R, Berto F. Global-local fatigue assessment of an ancient riveted metallic bridge based on submodelling of the critical detail. Fatigue Fract Eng Mater Struct 2019;42(2):546-60. https://doi. org $/ 10.1111 / \mathrm{ffe} .12930$.

[27] Stüssi F. Tragwerke aus aluminium. Springer Verlag; 1955.

[28] Neumann A, Weller J, Schmidt M, Liebich M. Aluminium-Schweißkonstruktionen, VEB Verlag Technik Berlin; 1966.

[29] Toasa Caiza PD, Ummenhofer T. A probabilistic Stüssi function for modelling the S$\mathrm{N}$ curves and its application on specimens made of steel S355J2 + N. Int J Fatigue 2018;117:121-34. https://doi.org/10.1016/j.ijfatigue.2018.07.041.

[30] Rinne H. The Weibull distribution. CRC Pr Inc; 2008.

[31] Mostaghel N, Byrd RA. Inversion of Ramberg-Osgood equation and description of hysteresis loops. Int J Non-Linear Mech 2002;37(8):1319-35. https://doi.org/10. 1016/S0020-7462(02)00025-2.

[32] Abdella K. Inversion of a full-range stress-strain relation for stainless steel alloys. Int J Non-Linear Mech 2006;41(3):456-63. https://doi.org/10.1016/j.ijnonlinmec. 2005.10.002.

[33] ASTM. A1008/A1008M-18 Standard Specification for Steel, Sheet, Cold-Rolled, Carbon, Structural, High-Strength Low-Alloy, High-Strength Low-Alloy with Improved Formability, Solution Hardened, and Bake Hardenable, Tech. rep., ASTM. Conshohocken, PA: International, West; 2018.

[34] Bathias C. There is no infinite fatigue life in metallic materials. Fatigue Fract Eng Mater Struct 1999;22(7):559-65. https://doi.org/10.1046/j.1460-2695.1999. 00183.x.

[35] Pyttel B, Schwerdt D, Berger C. Very high cycle fatigue - is there a fatigue limit? Int J Fatigue 2011;33(1):49-58. https://doi.org/10.1016/j.ijfatigue.2010.05.009.

[36] Toasa Caiza PD, Ummenhofer T. General probability weighted moments for the three-parameter Weibull distribution and their application in S-N curves modelling. Int J Fatigue 2011;33(12):1533-8. https://doi.org/10.1016/j.ijfatigue.2011.06. 009. 


\section{Repository KITopen}

Dies ist ein Postprint/begutachtetes Manuskript.

Empfohlene Zitierung:

Toasa Caiza, P. D.; Ummenhofer, T.

Probabilistic relationships between strain range, stress range and loading cycles. Application on ASTM A969 steel. 2020. International journal of fatigue, 137. doi: $10.5445 /$ IR/1000123484

Zitierung der Originalveröffentlichung:

Toasa Caiza, P. D.; Ummenhofer, T.

Probabilistic relationships between strain range, stress range and loading cycles. Application on ASTM A969 steel. 2020. International journal of fatigue, 137, 105626.

doi:10.1016/j.ijfatigue.2020.105626 